\title{
Desafios para uma força social emergente
}

\author{
JACOB GORENDER
}

$\mathrm{A}$ S CHAMADAS comemorações dos 500 anos do descobrimento colocaram sob a luz dos holofotes a questão da identidade nacional brasileira. Para surpresa dos promotores dos projetados festejos, as razões destes foram, desde o começo, contestadas. Afinal, que deveriam comemorar e festejar os índios remanescentes e os afro-brasileiros? Para índios e negros, o que representou a criação da entidade política denominada Brasil senão a tragédia de destruição da identidade original, de sofrimentos infindos e extermínio em massa?

Os acontecimentos de 22 de abril em Porto Seguro em nada tiveram o aspecto esperado numa celebração. O enorme aparato policial montado para garantir a solenidade oficial e as cenas de repressão de índios e semterra, na estrada de acesso à cidade, deixaram à mostra o antagonismo entre duas visões da história brasileira pós-descobrimento.

Não esteve em causa o sentimento patriótico do povo brasileiro. Tem sido dito que somos uma nação incompleta, cuja construção ainda está se fazendo. Apesar disso e de tantos fatores negativos, existe um sentimento patriótico difuso enraizado. Mas, certamente, o episódio manifestou a existência também de uma auto-identificação contraditória e conflituosa.

Por isso mesmo, comentando os episódios de Porto Seguro, Otavio Frias Filho pôde se referir à fraca auto-estima, à má consciência e mal-estar no mundo, que nos caracterizaria como brasileiros (Folha de S.Paulo, 27 abr. 2000). Se isto é verdade com relação aos setores mais perspicazes do establishment, que dizer dos oprimidos e espoliados de ontem e de hoje?

No fundo da nossa consciência social, em camadas mais abaixo do sentimento patriótico, a pretensão de festejar o descobrimento desencadeou os conflitos de uma identidade contraditória. Veio à tona a imensa dívida contraída pela classe dominante com os índios, os negros e os semterra. Para estes e para as grandes massas de assalariados urbanos, é muito difícil orgulhar-se de pertencer a uma sociedade tão iníqua como a brasileira. 
Certamente, a exposição da identidade nacional contraditória e conflituosa que provocou impacto tão intenso foi também motivada pelas circunstâncias conjunturais penosas em que se encontra o país. Após os anos 80, constatamos que os anos 90 igualmente se escoaram como mais uma década perdida. No quadro de um crescimento nulo ou medíocre, a afirmação tão repetida de que temos uma das sociedades mais desiguais do planeta não parece senão um atestado de conformismo. Se a classe dominante se conforma e até reclama que lhe devolvam os anéis cedidos em passado tão recente, deverão as classes e os segmentos sociais dominados também se conformar e resignar-se à lamentação?

Estamos diante de um desafio, acerca do qual precisamos ter clareza.

O Brasil, como nação, paga agora o alto preço do desenvolvimento econômico realizado nos limites estritos de uma modernização conservadora. Ao invés de eliminar mazelas estruturais, o desenvolvimento as tornou mais agudas e a elas acrescentou novas mazelas. Ao invés de conduzir à independência no contexto internacional, agravou-se a dependência do país no mundo globalizado de hoje.

A situação atual veio evidenciar que o crescimento econômico não ergue a nação a um patamar de poder e bem-estar se não vier acompanhado de mudanças na estrutura social. Sem tais mudanças, o próprio crescimento entra num beco sem saída e se compromete perigosamente.

Durante cerca de 70 anos, neste século, a economia brasileira apresentou uma das maiores taxas mundiais de crescimento do PIB. No decurso dessas sete décadas, com aceleração inaudita, a sociedade que se dizia essencialmente agrícola se tornou industrializada e urbanizada. Com $70 \%$ da população na área rural, ainda nos anos 40 , temos agora $80 \%$ da população nas áreas urbanas.

O rápido crescimento econômico veio acompanhado de um esforço intenso de atualização tecnológica. Entramos com grande atraso na segunda revolução tecnológica, iniciada no final do século passado nos países capitalistas desenvolvidos. Mas, ao termino da década dos 80 do século XX, a economia brasileira dominava os processos técnicos da eletricidade, do motor a combustão interna e da indústria química. Na exportação brasileira, passaram a predominar os manufaturados, incluindo itens de tecnologia sofisticada. 
A base estreita e precária deste crescimento se revelou logo no começo da década dos 80. Manifestou-se sob três aspectos principais, dois deles endógenos. Um terceiro, exógeno.

O primeiro aspecto endógeno consistiu no fato de que tivemos, no Brasil, um dos casos mais típicos de desenvolvimento endividado. Foi preciso contrair uma dívida externa pesada para completar a insuficiência da poupança nacional e manter as altas taxas de crescimento. Este se sustentava no que se chamou de tripé, constituído pelo Estado, pelo capital privado brasileiro e pelo capital privado estrangeiro. O Estado se incumbiu de montar a infra-estrutura de meios de transporte e comunicação e de fontes de energia, bem como a indústria de matérias-primas básicas. A receita de origem nacional, obtida pela tributação e pela dívida interna, precisou ser complementada com o aporte dos empréstimos no exterior. Como houvesse, na época, grande liqüidez financeira internacional, originária de petro e de eurodólares, não foi difícil conseguir os empréstimos. A ressaca veio em 1979, quando o banco central americano (FED) triplicou a taxa de juros visando conter o processo inflacionário em curso na economia norte-americana. Uma vez que os empréstimos externos haviam sido contraídos a juros variáveis, o Estado brasileiro se defrontou, subitamente, com a obrigação de pagar juros três vezes maiores e viu a dívida externa inchar desabaladamente. Para enfrentar o problema, e sob pressão dos credores, foi preciso inverter a orientação do comércio exterior e passar do déficit para o superávit da balança comercial. Comprimiram-se importações necessárias à cadeia produtiva interna e intensificou-se o esforço exportador, com vistas à obtenção das divisas requeridas pelo serviço da dívida. Caiu, assim, a taxa de poupança nacional e de formação fixa do capital produtivo. Emperrou-se o desenvolvimento.

O segundo fator endógeno residiu no recrudescimento da inflação. Responsável por empreendimentos de grande porte e fonte praticamente única do financiamento a longo prazo à iniciativa privada, o Estado apelou aos mecanismos inflacionários a fim de prover os meios monetários exigidos pelo crescimento econômico. Pouco depois de debelada, à altura de 1973, a inflação herdada do período pré-64, já se iniciava um novo ciclo de inflação, que atingia os 40\%, em 1980, e mais do que triplicava na gestão de Delfim Netto no ministério da Fazenda, logo em seguida. Em 1994, já as finanças nacionais estavam à beira da hiper-inflação.

As medidas que acompanharam o lançamento do real conseguiram debelar a espiral inflacionária e impor certa estabilidade monetária. Fize- 
ram-no, porém, com aplicação de um plano econômico-financeiro de corte neoliberal, o qual, hoje, se apresenta claramente como uma armadilha.

Depois de securitizada pelo chamado Plano Brady, o pagamento da dívida externa perdeu o caráter de ameaça iminente, mas passou a significar pesado compromisso anual referente ao principal e aos juros. As autoridades monetárias precisam de atenção ininterrupta para evitar que o compromisso se agrave com o déficit comercial e outros itens do balanço de pagamentos. Ao mesmo tempo, a política anti-inflacionária estrita impõe cortes orçamentários, que, como seria de esperar, incidem nos escassos e já esquálidos programas sociais. Semelhante política, acrescida das privatizações generosas, se acredita a única que permite esperar o ingresso de capital estrangeiro em escala suficiente para cobrir o déficit nas transações correntes do balanço de pagamentos.

Assim, consegue-se segurar a estabilidade monetária e evitar o colapso das contas externas. Mas o preço tem sido o desemprego estrutural em proporção jamais conhecida na história econômica do país, o sufoco da empresa nacional, a ampliação da área de domínio do capital estrangeiro e a elevação acelerada das remessas de lucros das empresas multinacionais às suas matrizes. O melhor que se vislumbra no horizonte mais próximo é um crescimento medíocre para o ano 2000, de todo modo insuficiente para as carências reprimidas da economia e da população brasileira.

Tal estilo de comportamento nos deixa à mercê do capital financeiro internacional. O país se vê enredado num círculo vicioso, aparentemente sem saída efetiva. Quanto mais pagamos, mais devemos. Quanto mais capital estrangeiro entra, mais capital nacional sai. Quanto mais estável parece o real, mais crescem os riscos de instabilidade. Quanto mais equilibrados o orçamento e o balanço de pagamentos, tanto menos favorável a situação da empresa nacional e mais ásperas as condições de vida da grande maioria dos trabalhadores. As mais recentes pesquisas estatísticas revelam a permanência da enorme desigualdade entre os estratos de renda mais alta e mais baixa. Aos velhos problemas se ajuntam os novos e mais graves.

Até os anos 70, a economia brasileira conseguia crescer razoavelmente, apoiada no tripé já mencionado. Agora, porém, após a hiper-inflação e a ressaca monetarista, que se lhe seguiu, encurtaram os dois pés, representados pelo Estado e pelo capital privado nacional, enquanto se alongou, e continua a alongar-se, o pé representado pelo capital estrangeiro. O sistema de investimentos anterior foi subvertido, sem que o sucedesse um sistema adequado às novas circunstâncias. $\mathrm{O}$ padrão da economia brasileira adquiriu a característica de um passo contido, vacilante e trôpego. 
Daí um quadro sombrio que se traduz nas greves de trabalhadores manuais e intelectuais, desde caminhoneiros e metalúrgicos a professores. Ganham feição mais aguda as ações dos camponeses sem-terra. Este quadro contribui para compor expectativas decididamente pessimistas em face das facções políticas no poder e até dos políticos em geral, estimulando propensões populares antidemocráticas. Enfrentamos, sem dúvida, um desafio que precisa ser equacionado do ponto de vista daqueles, que hoje são os desprivilegiados.

A superação dos dilemas presentes não se fará, segundo penso, com a simples aceleração da taxa de crescimento econômico. Certamente, precisamos dele e, dadas as carências reprimidas, deverá ser um crescimento a taxas comparáveis às dos anos de desenvolvimento do passado recente. Mas, como podemos inferir da crise política que motivou o golpe militar de 1964, o crescimento econômico, fixado na modernização conservadora, trará novas crises políticas, cujos desenlaces poderão ser tão ou mais negativos do que a de 1964. É indispensável ter em vista soluções para os problemas de fundo, que fazem parte do nosso déficit social.

Em primeiro lugar, o crescimento econômico precisará contribuir para reduzir substancialmente, até eliminar, o desemprego estrutural, que se abateu sobre os assalariados. Sob tal aspecto, precisam ser consideradas medidas como a diminuição da jornada de trabalho e a reversão para o trabalho formal de grandes contingentes abrangidos pelo trabalho informal.

Associada intimamente à questão do desemprego estrutural, a agenda nacional propõe a urgência de uma reforma agrária efetiva e profunda. $\mathrm{O}$ Brasil é um dos pouquíssimos países de economia industrializada, que nunca fez reforma agrária. Todos os países capitalistas desenvolvidos implementaram uma reforma agrária, com maior ou menor radicalidade. A intensificação das lutas dos sem-terra e dos pequenos agricultores é apenas o sintoma dos males provocados pelo atraso histórico, na questão da reforma agrária, e da urgência da solução requerida. Com toda evidência, não pode surtir efeito duradouro a política de apagar incêndio usando o conta-gotas. No caso, faz-se preciso afastar raciocínios economicistas, acerca do efeito da distribuição de terras sobre a produção agrícola (como insistia a esquerda no passado), e considerar a reforma agrária primordialmente como necessidade social. O seu atendimento inclui obrigatoriamente a distribuição de terras, mas também o fornecimento de crédito, a instituição de canais de comercialização e a assistência agronômica aos novos proprietários fundiários e aos pequenos agricultores em geral. 
Juntamente com a redução da jornada de trabalho, a elevação dos salários, entre outras medidas, a reforma agrária certamente contribuirá para reduzir a enorme desigualdade social, que se tornou a marca internacional do país.

Com o objetivo não só de modernizar a economia, mas também de eliminar males sociais, que se traduzem em miséria e criminalidade, é absolutamente indispensável que o Estado recupere a iniciativa em todos os domínios que dizem respeito ao desenvolvimento econômico e ao bemestar da população. Já ficou demasiado evidente o atoleiro em que o ideário neoliberal afundou economia e sociedade no Brasil. Cumpre evitar que seja torrado na privatização selvagem o que ainda ficou de fora, como a Petrobrás e o Banco do Brasil. O Estado deve readquirir a capacidade de investimento e orientar-se por um projeto de benefícios diretamente sociais, nas áreas da saúde, da educação, da habitação, da previdência, do saneamento básico, do lazer. Tudo isto implica mudança radical nas prioridades orçamentárias, inversão de orientação em favor não da estabilidade monetária como fim em si, porém do desenvolvimento como fim e a estabilidade monetária como meio.

Obviamente, uma visão desta ordem não se coaduna com o veredito acerca da obsolescência do Estado nacional. Enfraquecidos estão os Estados nacionais que já eram fracos muito antes da atual onda globalizante e se debilitaram ainda mais com ela. Nos países desenvolvidos, os Estados nacionais podem ter perdido algumas prerrogativas diante do incremento do poder do capital financeiro e das empresas multinacionais, porém continuam como o sujeito político fundamental na área internacional, organização imprescindível ao ordenamento econômico, político e jurídico no plano mundial. No entanto, os Estados nacionais exercem sua função de sujeito político eficiente somente ali onde a sociedade produz a vontade política interna correspondente a aspirações de existência autônoma. Onde tais aspirações perdem capacidade de afirmação, reduzem-se ou anulam-se as energias necessárias ao Estado nacional na fase globalizante atual.

O Estado nacional é necessário ainda para garantir o desenvolvimento econômico compatibilizado com a proteção dos ecossistemas, com a preservação do meio ambiente natural indispensável à sobrevivência da espécie humana. Não se pode esperar que os imperativos ecológicos sejam espontaneamente respeitados pelos interesses privados. A própria obrigação de conservação do meio ambiente planetário aponta para a necessidade da atuação do Estado nacional. O que é mais do que evidente no caso do Brasil, país em que são exacerbados os interesses privados na devastação da Amazônia e na depredação do que nos resta de patrimônio natural. 
Se o pé representado pelo Estado precisa reconquistar sua firmeza, e o mesmo se pode dizer também da iniciativa privada nacional; na medida em que esta última ainda seja capaz de servir a um projeto progressista, é evidente que o capital estrangeiro só poderá se inserir neste projeto submetido à orientação prevista por uma legislação, que assegure à nação a capacidade de decisão autônoma sobre sua economia.

Capacidade de decisão autônoma implica força tecnológica endógena. Sob este aspecto, ganha relevo o fortalecimento das universidades públicas, como principais centros de pesquisa científica e tecnológica. Não está fora das possibilidades factíveis o objetivo de fazer do Brasil um centro de ciência e tecnologia de primeira ordem. O empenho neste objetivo certamente incentivará a energia criadora da intelligentsia brasileira.

Não se trata, enfim, de isolar-se de um mundo em processo de globalização, mas de decidir com independência nosso rumo próprio neste quadro internacional. Um país como o Brasil não pode aceitar resignadamente a posição de marginal ou de pária na arena mundial. Sem cair nas miragens de Brasil-potência ou nas visões hegemônicas regionais, o país carece de um projeto que o alce à condição de país próspero no qual se abriga uma população instruída e saudável.

O cerne do desafio não está somente na definição dos problemas, mas também na convicção de que tais problemas só poderão ser resolvidos por um bloco de forças sociais completamente diverso deste, que domina e assola o país ininterruptamente, há tanto tempo. Sem um novo bloco no poder, que represente os assalariados, continuaremos a patinar e a soçobrar. $\mathrm{Na}$ verdade, a equação que hoje se apresenta é a de motivar, na área urbana, um conjunto de forças sociais e políticas que, em aliança com as forças já em mobilização na área rural, venha a constituir um novo bloco no poder. Um bloco no qual os assalariados não sejam os únicos representados, porém os protagonistas hegemônicos. Ter ou não ter uma força social emergente transformadora - este o âmago do desafio que a história nos lança e do qual depende nosso futuro no século XXI.

Jacob Gorender é historiador. Entre outras obras, é autor de Marxismo sem utopia (Ática). Foi professor visitante do Instituto de Estudos Avançados da USP. 